\title{
Exploring the Linkage Between Commodity Chain Profile and Performance: A Case Study of Sawn Wood in Uganda
}

\author{
Robert Kyeyune Kambugu ${ }^{*}, 1$, Abwoli Yabezi Banana² and Mackay Okure ${ }^{3}$ \\ ${ }^{I}$ Department of Agricultural and Biosystems Engineering, College of Agricultural and Environmental Sciences, \\ Makerere University P.O. Box 7062, Kampala, Uganda \\ ${ }^{2}$ Department of Forestry, Biodiversity and Tourism, College of Agricultural and Environmental Sciences, Makerere \\ University P.O. Box 7062, Kampala, Uganda \\ ${ }^{3}$ Department of Mechanical Engineering, College of Engineering, Design, Art and Technology, Makerere University, \\ P.O. Box 7062, Kampala, Uganda
}

\begin{abstract}
Secure supply of wood remains a challenge partly due to resource conservation efforts that have failed to focus on the sawn wood supply chain as a whole. This study investigated the influence of sawn wood commodity chain profile on its performance. Data were collected from the production and distribution chain of 35 production units selected randomly. Production batches comprising of at least fifteen logs each were used at each unit to collect data on volume recovery factor, value addition and revenue distribution between participants in the unit's distribution chain. One-way multivariate analysis of variance was used to test the hypothesis that there is no difference in performance parameters between the sawn wood commodity chain channels. Results revealed a significant multivariate effect $(\mathrm{p}<0.05)$ for channel of operation on performance thus rejecting the null hypothesis. Univariate ANOVA showed significant difference $(p<0.05)$ between the channels on all the three performance parameters. It was recommended that factors influencing the performance parameters be investigated and standards established for benchmarking; the three performance dimensions be integrated into a single index for assessing the overall performance; and the impact of sawn wood commodity chain performance on sawn wood supply sustainability be investigated.
\end{abstract}

Keywords: Distribution equity, efficiency, sustainability, timber commodity chain, value addition.

\section{INTRODUCTION}

The wood resource base for timber production in Uganda has been declining since the mid 1970s following the collapse of the sawmilling industry and the emergence of artisan timber production [1,2]. Consequently, the sustainability of sawn wood supply in Uganda is threatened by the prevailing wood resource scarcity as available forests cannot sustain the level of harvesting required to satisfy the steadily increasing sawn wood demand [1-3]. Considerable effort has been put on resource conservation and the improvement of processing efficiency but secure supply of wood remains a challenge. This can be partly attributed to the focus on forest protection and the efficiency of the production stage instead of the sawn wood supply chain in its totality. While it is acknowledged that performance of the sawn wood sector in Sub-Sahara Africa in terms of conversion efficiency is generally poor [4], the strategies adopted in Uganda that focus on selected sections of the timber supply chain and virtually ignoring others may not resolve the resource scarcity challenge.

A supply chain is a network of business entities working together to facilitate the flow of material, information,

Address correspondence to this author at the Department of Agricultural and Biosystems Engineering, College of Agriculture and Environmental Sciences, Uganda; Tel: +256 772621 863; Fax: +256 414531 641;

E-mail:kambugu@forest.mak.ac.ug money and property rights across organizational boundaries $[5,6]$. On the other hand, a commodity chain is a series of interlinked exchanges through which a commodity and its constituents pass from extraction to end use; commodity chains serve as conduits through which commercialized natural resources are ushered from the land to their final users [7]. Thus the sawn wood commodity chain can be viewed as a supply chain that facilitates the production and distribution of timber. The timber commodity chain in Uganda consists of three channels (Fig. 1). In channel 1, sawn wood producers, mainly sawmillers, obtain trees from forest reserves through a public bidding system, produce sawn wood and transport it to urban timber markets. In channel 3, sawn wood producers, mainly pit-sawing contractors, obtain one-year concessions to harvest from designated areas on private land within a district local government. They employ pit-sawyers to produce the sawn wood after which it is transported to markets. Channel 2 is a conduit for illegal timber produced by independent pitsawyers, operating either on casual license or illegally, and chainsaw millers. The later actors operate illegally. Actors in channel 2 operate extensively on private land and in reserves albeit at a small scale. After conversion, the sawn wood is distributed locally or traded underground in urban areas as it is a target for confiscation by regulatory authorities [8].

Little is known about the performance of the above sawn wood commodity chain. This can be attributed to the current 


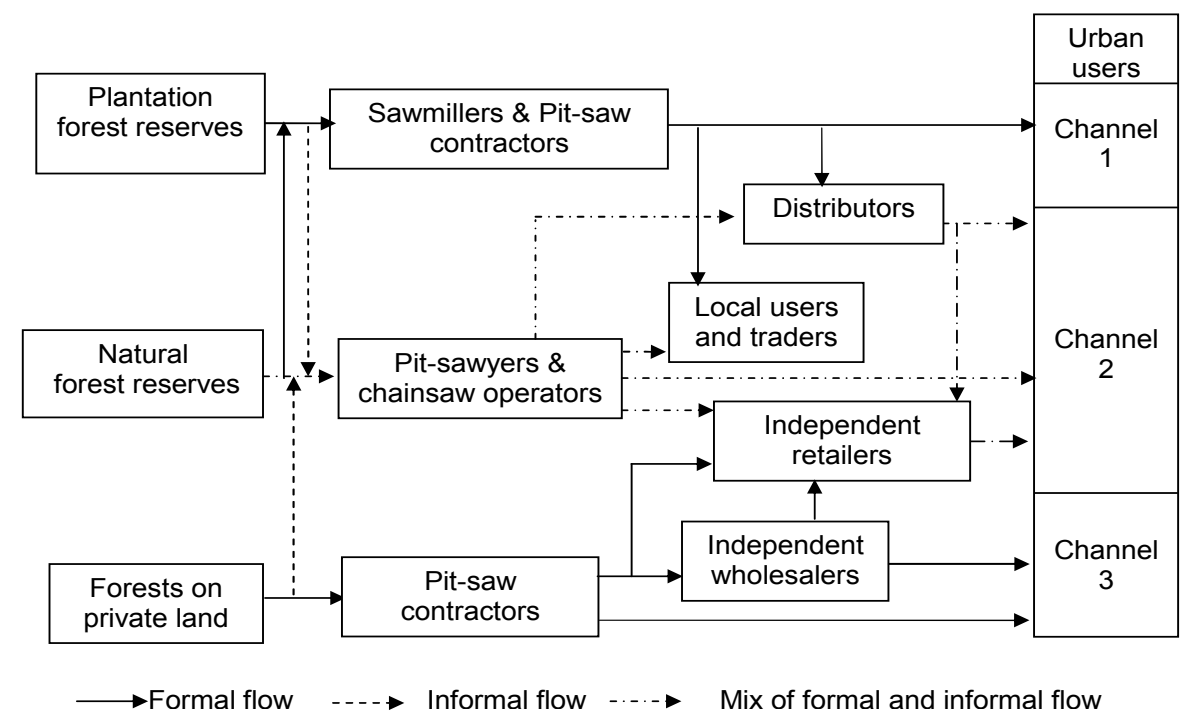

Fig. (1). Sawn wood production and distribution system [8].

focus on particular segments of the chain, particularly sawn wood production [9]. The measures used are restricted to such segments, with no measurement of overall supply chain performance. It has been noted that effective evaluation of supply chain performance requires the use of integrated measures that are cross-functional and can be applied to the entire process in order to avoid optimization at one point in the chain without considering potential consequences at other points [6]. A wide range of measures for assessing supply chain performance have been developed. However, the traditional performance measures used for supply chain analysis focus on issues relating to logistics such as cost, activity time, inventory level, product quality, customer responsiveness and flexibility [10-13]. These are important characteristics of a supply chain but do not address natural resource commodity chain challenges such as resource shortages and the fair distribution of economic gains among the chain participants. According to [14], the success of a commodity system depends on standardisation of the commodity and its sale at a low price, two aspects that make commodities accessible and dependable but not sustainable because they tend to drive commodity systems towards resource depletion, price instability and inequity. An examination resource sustainability in commodity systems using the sawmill industry as a case study by [15] demonstrated the potential of the industry to overshoot the capacity of the forest resource and showed that commonly advocated policies in response to resource shortages could not solve the challenge.

As wood becomes increasingly scarce, efficiency in its utilization is a primary concern in timber manufacturing and this should be viewed in terms of both increased yields and revenues for the mills [16]. Thus the basic philosophy for the timber production and distribution system should be the optimisation of volume and value yield [17]. Value yield can be calculated as the sum of all revenues generated from one cubic meter of solid wood [18, 19]. On the other hand, volume yield which is expressed as a recovery percentage or a wood consumption factor relates the volume of timber to volume of logs from which the timber is manufactured [18,
20]. These traditional measures of performance in the timber production chain focus on the production stage only. This study investigated the influence of sawn wood commodity chain profile on its performance. The performance of the sawn wood commodity chain was evaluated on the basis of wood conversion capability, value addition potential and distribution of value added between the commodity chain participants. It was hypothesised that there is no difference in the performance of the sawn wood commodity chain channels.

\section{METHODS}

\section{Data Collection}

Data were collected from the production and distribution chain of 35 production units selected using stratified random sampling with the channel of operation as the strata. A production batch comprising of at least fifteen $\operatorname{logs}$ for manual operations and thirty logs for mechanised operations were used at each production unit to collect data on log size (small and large diameter, length), timber size (nominal cross-section and actual length), log cost, and timber price along the distribution chain (ex-mill, wholesale and retail). These data were used to ascertain three performance parameters for the sawn wood commodity chain which included a volume recovery factor (numerically equal to the log volume required to produce a unit volume of timber), a value amplification factor (numerically equal to the number of times the value of a unit volume of logs is amplified by the commodity channel) and a distribution equity index (using timber revenue concentration as a dummy for distribution equity).

\section{Data Analysis}

Multivariate analysis of variance was used to test the hypothesis that there is no difference in performance parameters between the sawn wood commodity chain channels. The performance parameters were obtained for each channel of the commodity chain using the formulae 
below. Parameters for each production unit were obtained as simple average values for the logs processed and the resulting timber while the parameters for each channel were obtained as simple average values for the units in that channel.

$$
\begin{aligned}
& \mathrm{VRF}=\frac{\mathrm{VL}}{\mathrm{VT}} \\
& \mathrm{VL}=\sum_{i=1}^{m}\left[\frac{\pi H_{i}}{8}\left(d t_{i}^{2}+d b_{i}^{2}\right)\right] \\
& V T=\sum_{j=1}^{n}\left(L_{j} \times v_{j}\right) \\
& V A F=\frac{P T}{P L} \\
& P T=\sum_{j=1}^{n}\left(p t_{j 4} \times L_{j}\right) \\
& P L=V L \times p l \\
& D E I=\sum_{A l l k} S_{k}^{2} \\
& S_{k}=\frac{I_{k}}{P T} \quad \text { for } k=1 \\
& I_{k}= \begin{cases}P L & \text { otherwise } \\
\sum_{j=1}^{n}\left(p t_{j k}-p t_{j k-1}\right) \times L\end{cases}
\end{aligned}
$$

where for each production unit:

$\mathrm{VRF}=$ volume recovery factor;

$\mathrm{VL}=$ input $\log$ volume $\left(\mathrm{m}^{3}\right)$ in a $\log$ batch;

$\mathrm{VT}=$ output timber volume $\left(\mathrm{m}^{3}\right)$ from a log batch;

$\mathrm{H}_{\mathrm{i}}=$ length (m) of $\log \mathrm{i}$;

$\mathrm{dt}_{\mathrm{i}}$ and $\mathrm{db}_{\mathrm{i}}$ are the small-end and large-end diameters (m) respectively of $\log \mathrm{i}$;

$\mathrm{L}_{\mathrm{j}}$ is the total timber length (running metres) for timber size $\mathrm{j}$ from a log batch;

$\mathrm{v}_{\mathrm{j}}=$ volume per running metre $\left(\mathrm{m}^{3} / \mathrm{m}\right)$ for timber size $\mathrm{j}$;

$\mathrm{m}=$ number of logs processed in a log batch;

$\mathrm{n}=$ number of timber sizes produced from a log batch;

$\mathrm{VAF}=$ value amplification factor;

$\mathrm{PT}=$ market value of timber from a log batch;

$\mathrm{PL}=$ stumpage value of logs in a log batch;

$\mathrm{pt}_{\mathrm{jk}}=$ average timber price per running metre for timber size $\mathrm{j}$ at stage k;

$\mathrm{pl}=$ average stumpage price per $\mathrm{m}^{3}$ of logs;

$\mathrm{DEI}=$ distribution equity index;

$\mathrm{S}_{\mathrm{k}}=$ ratio of gross income shared by stage $\mathrm{k}$ to the market value of timber;

$\mathrm{I}_{\mathrm{k}}=$ gross income shared by stage $\mathrm{k}$ of the sawn wood commodity chain; $\mathrm{k}=1$ (tree supply), 2 (timber production), 3 (wholesale distribution), 4 (retail distribution).

\section{RESULTS}

Analysis shows that the mean volume of wood required to produce a cubic metre of timber was lower in channel 1 compared to channels 2 and 3 , with channel 2 requiring the highest volume. Similarly channel 3 exhibited the highest value amplification potential and channel 1 the lowest while in terms of sharing timber revenue, channel 3 exhibited a relatively more even distribution compared to the other channels, with channel 2 having a higher revenue concentration (Table 1). Taking into account the fact that tree owners barely participate beyond tree supply while producers invariably do the distribution as well, the highest share of revenues captured by a single category of actors ranged between $57-74 \%, 48-78 \%$ and $42-65 \%$ in channels 2 , 3 and 1 respectively (Fig. 2). When this is taken into account, the distribution equity index would change to 0.473 , 0.602 and 0.608 for channels 1,2 and 3 respectively indicating higher revenue concentrations for channels 2 and 3 compared to channel 1. A one-way ANOVA for distribution equity index indicates significant difference between the channels $\left(F_{2,32}=117.6, p<0.05\right)$ with posthoc tests showing that channels 2 and 3 are not significantly different from each other but both are significantly different from channel 1.

Table 1. Performance of the Sawn Wood Commodity Chain

\begin{tabular}{|c|c|c|c|c|}
\hline \multirow{2}{*}{ Channel } & \multirow{2}{*}{$\mathbf{N}$} & \multicolumn{3}{|c|}{ Mean Performance* } \\
\cline { 3 - 5 } & & VRF & VAF & DEI \\
\hline \hline 1 & 15 & $3.030(0.0542)$ & $2.469(0.0545)$ & $0.365(0.0075)$ \\
\hline 2 & 8 & $3.251(0.0675)$ & $5.658(0.6180)$ & $0.412(0.0175)$ \\
\hline 3 & 12 & $3.154(0.1152)$ & $7.788(0.1152)$ & $0.326(0.0047)$ \\
\hline
\end{tabular}

A one-way MANOVA was conducted to assess the omnibus performance difference between channels of the sawn wood commodity chain (Table 2). Values in the row for Table $\mathbf{2}$ labelled 'Channels' indicate whether means of performance parameters differ significantly between channels. The results show a significant $(p<0.05)$ multivariate effect by channel of operation thus rejecting the null hypothesis that there is no difference in performance between channels of the sawn wood commodity chain. Univariate tests were carried out to ascertain the source of the omnibus multivariate effect. Results of these ANOVAs (Table 3) compare mean performance of the individual performance measures for each channel. According to the values for the row of Table 3 labelled 'Channels', all dependent variables (VRF, VAF \& DEI) showed significant $(\mathrm{p}<0.05)$ effect of channel of operation on all the three performance parameters. This suggests that channels of the sawn wood commodity chain differ in regard to the amount of raw wood required to produce a unit volume of timber, amplification of the value of wood passing through them and the distribution between participants of the revenue arising from the timber. Post-hoc analysis (Table 4) revealed significant pair wise differences between channels of the sawn wood commodity 


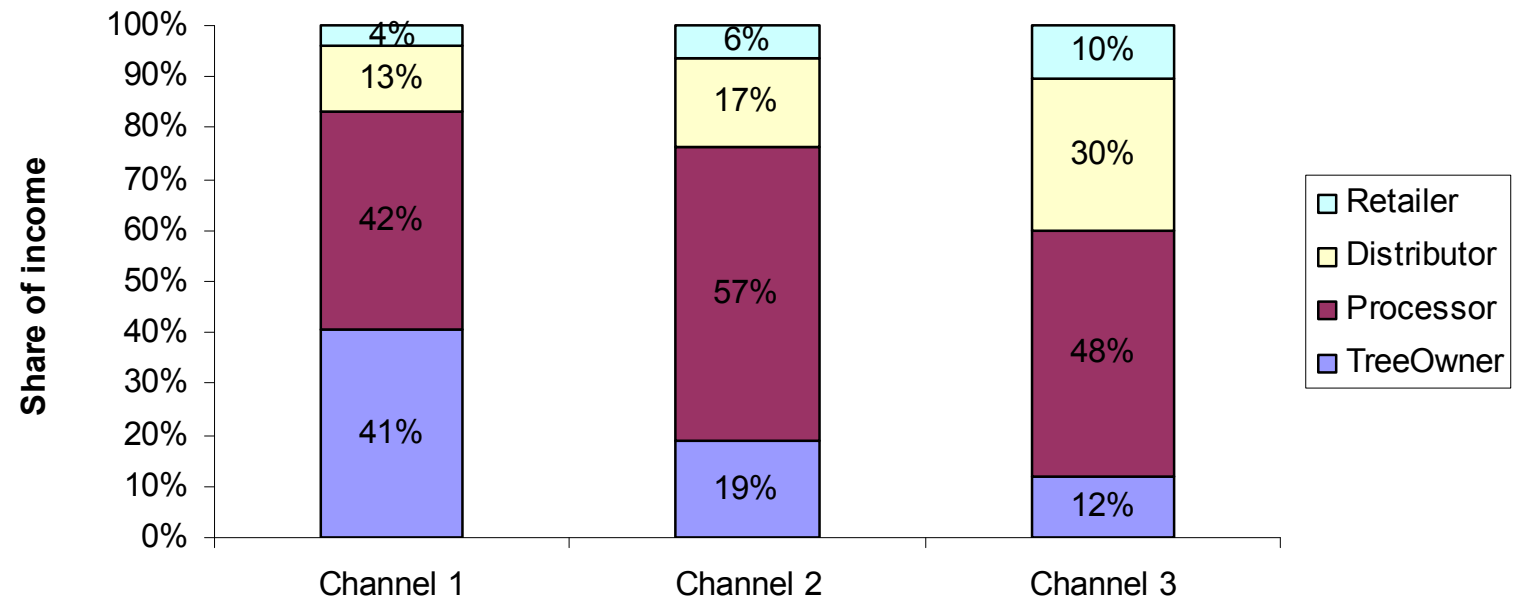

Fig. (2). Share of timber revenue between sawn wood commodity chain participants.

Table 2. Multivariate Tests

\begin{tabular}{|c|c|c|c|c|c|c|c|}
\hline \multicolumn{2}{|r|}{ Effect } & Value & $\mathbf{F}$ & $\begin{array}{c}\text { Hypothesis } \\
\text { df }\end{array}$ & $\begin{array}{c}\text { Error } \\
\text { df }\end{array}$ & Sig. & $\begin{array}{c}\text { Partial Eta } \\
\text { Souared }\end{array}$ \\
\hline \multirow{4}{*}{ Intercept } & Pillai's Trace & .983 & 613.1 & 3.000 & 31.000 & .000 & .983 \\
\hline & Wilks' Lambda & .017 & 613.1 & 3.000 & 31.000 & .000 & .983 \\
\hline & Hotelling's Trace & 59.335 & 613.1 & 3.000 & 31.000 & .000 & .983 \\
\hline & Roy's Largest Root & 59.335 & 613.1 & 3.000 & 31.000 & .000 & .983 \\
\hline \multirow{4}{*}{ Channel } & Pillai's Trace & .870 & 68.941 & 3.000 & 31.000 & .000 & .870 \\
\hline & Wilks' Lambda & .130 & 68.941 & 3.000 & 31.000 & .000 & .870 \\
\hline & Hotelling's Trace & 6.672 & 68.941 & 3.000 & 31.000 & .000 & .870 \\
\hline & Roy's Largest Root & 6.672 & 68.941 & 3.000 & 31.000 & .000 & .870 \\
\hline
\end{tabular}

Table 3. Univariate ANOVA for Performance Parameters

\begin{tabular}{|c|c|c|c|c|c|c|c|}
\hline Source & Dependent Variable & Sum of Squares & Df & Mean Square & $\mathbf{F}$ & Sig. & Eta Squared \\
\hline \multirow{3}{*}{ Intercept } & VRF & 323.751 & 1 & 323.751 & 10168.846 & 0.000 & 0.997 \\
\hline & VAF & 921.022 & 1 & 921.022 & 1094.274 & 0.000 & 0.972 \\
\hline & DEI & 4.427 & 1 & 4.427 & 6981.296 & 0.000 & 0.995 \\
\hline \multirow{3}{*}{ Channel } & VRF & 0.274 & 2 & 0.137 & 4.300 & 0.022 & 0.212 \\
\hline & VAF & 192.802 & 2 & 96.401 & 114.535 & 0.000 & 0.877 \\
\hline & DEI & 0.035 & 2 & 0.018 & 27.637 & 0.000 & 0.633 \\
\hline \multirow{3}{*}{ Error } & VRF & 1.019 & 32 & 0.039 & & & \\
\hline & VAF & 26.934 & 32 & 0.842 & & & \\
\hline & DEI & 0.020 & 32 & 0.001 & & & \\
\hline \multirow{3}{*}{ Total } & VRF & 342.696 & 35 & & & & \\
\hline & VAF & 1102.272 & 35 & & & & \\
\hline & DEI & 4.656 & 35 & & & & \\
\hline
\end{tabular}

chain for all the performance parameters except VRF between channels 2 and 3, and channels 1 and 3 .

\section{DISCUSSION}

Although analysis shows that the volume recovery factor differs significantly between channels of the sawn wood commodity chain, it is evident that a relatively large volume of wood is consumed in producing timber in all the three channels. The high volume of wood required per unit timber volume can be attributed to the inefficient technology used for timber production. These include swivel mobile sawmills in channel 1, pitsaws in channel 3 and mixture of chainsaws, saw benches and pitsaws in channel 2. Owing to the declining wood inventory, only swivel sawmills can be 
Table 4. Pair Wise Comparison Between Channels

\begin{tabular}{|c|c|c|c|c|c|}
\hline \multirow{2}{*}{ Variable } & \multicolumn{2}{|c|}{ Channel } & \multirow{2}{*}{ Mean Difference (I-J) } & \multirow{2}{*}{ SE } & \multirow{2}{*}{ Sig. } \\
\hline & I & $\mathbf{J}$ & & & \\
\hline \multirow{3}{*}{ VRF } & 1 & 2 & $-0.222 *$ & 0.078 & 0.008 \\
\hline & & 3 & -0.125 & 0.069 & 0.081 \\
\hline & 2 & 3 & 0.097 & 0.081 & 0.243 \\
\hline \multirow{3}{*}{ VAF } & 1 & 2 & $-3.189^{*}$ & 0.402 & 0.000 \\
\hline & & 3 & $-5.139 *$ & 0.355 & 0.000 \\
\hline & 2 & 3 & $-2.130 *$ & 0.419 & 0.000 \\
\hline \multirow{3}{*}{ DEI } & 1 & 2 & $0.046^{*}$ & 0.011 & 0.000 \\
\hline & & 3 & $0.039^{*}$ & 0.010 & 0.000 \\
\hline & 2 & 3 & $0.085^{*}$ & 0.011 & 0.000 \\
\hline
\end{tabular}

*Significant mean difference at $5 \%$ level; $\mathrm{SE}=$ standard error.

viably operated due to their small size and these have been noted to be inefficient [9]. Similarly pit-sawing and freehand chainsaw milling have been noted to be wasteful [2]. The variation in volume of raw wood required can be attributed to differences in the nature of wood processed. Channel 1 actors deal with plantation-grown softwood resource in reserves which have trees that are of relatively good quality compared to trees growing in natural forests and on-farm, which actors in channel 3 handle. Channel 2 is a mixture of trees from all sources and would have had favourable volume recovery as timber producers in this channel are relatively selective in regard to the trees they process. However some of the actors in this channel use inefficient equipment such as free-hand operated chainsaws that result in high levels of waste.

The value amplification factor is a comparison of the value of timber to the value of logs from which it was processed. It is a value-free parameter that can be used to assess the value addition potential of the channel through which the timber is produced and distributed. Analysis has shown a significant difference in value amplification potential of the sawn wood commodity chain channels. This can be attributed to the differences in nature of wood processed which, for channels 1 and 3 attracts different prices while in channel 2 the actors have access to relatively low cost (and sometimes free) wood as a result of their informal operations. Channel 3 has the highest value amplification factor followed by channel 2 while channel 1 had the least (Table 1). This however doesn't necessarily arise out of superb operations that lead to value creation in channels 1 and 2 but rather to the low value of logs in these channels. Examination of Fig. (2) indicates that in channels 3 and 2 , the value of $\operatorname{logs}$ constitutes only $12 \%$ and $19 \%$ respectively of the value of timber extracted from the logs while in channel 1 it is $41 \%$. Thus logs through channels 2 and 3 have low inherent value and this can partly explain the high volume recovery factor because actors in these channels can still breakeven even with low timber recovery. However this is not good for sustaining sawn wood production because low log values lead to low inherent value for forest land which leads to its clearance for alternative enterprises such as agriculture. This may explain the high rate of deforestation particularly on private land from where channel 2 and 3 operators source their wood.

The distribution equity index, an indicator of how the timber revenues are distributed between participants was significantly different between the channels indicating that the revenue is shared differently in the three channels. Channel 2 had the highest value indicating a relatively higher revenue concentration while channel 3 had the lowest value indicating a more uniform distribution relative to the other channels. While further research would be required to ascertain what would constitute an equitable distribution of the timber revenues among participants in the commodity chain, it is evident (Fig. 2) that tree suppliers in channels 2 and 3 get a disproportionately low share of the timber revenue compared to their counterparts in channel 1. In all the three channels, timber producers take the largest portion of the revenues. According to [9], timber producers barely participate in tree supply/planting but in most cases integrate wholesale distribution in their timber production business. When this is taken into account, it would imply that their share of timber revenues can range between $55 \%$ in channel 1 to $78 \%$ in channel 2 . A high proportion of revenues shared by this link of the sawn wood commodity chain could be attracting more actors to participate in the link and encourages illegal harvesting when such actors fail to get operating licenses. The high share of revenues by the tree supply link in channel 1 can be attributed to the near monopoly supply in this channel since, at the moment, mature plantations are only found in government reserves. On the other hand, tree suppliers in channels 2 and 3 are small scale forest, woodlot or farm owners each selling their trees individually to the timber producers and as such have limited bargaining power. Moreover, according to [1], such forest owners are often ignorant of market prices and frequently sell their trees at low prices. While the timber producers may take advantage of this to make gains, low wood prices for tree suppliers may not be sustainable as already noted above. This also has implications for the current timber woodlots and plantations being widely established on private land in that unless these tree growers come together to have a collective voice and share information, they stand to gain little from their efforts. 


\section{CONCLUSION AND RECOMMENDATIONS}

This study has demonstrated that there is a significant difference in the performance of channels of the sawn wood commodity chain in relation to the volume of wood required to produce a unit volume of timber, value addition potential and the share of revenues arising from the sawn wood commodity chain. In the absence of benchmarks, no particular channel can be recommended as a model for sawn wood production and distribution on all the three parameters. Generally all the three channels need to address the high wood consumption, the low value addition potential and inequitable distribution of timber revenues especially to the tree supply link to foster sustainable tree supply. It is recommended that the factors that influence performance dimensions be investigated and standards established against which performance of the sawn wood commodity chain can be benchmarked; the three performance dimensions be integrated into a single index that can be used to assess the overall performance of the sawn wood commodity channels and the chain as a whole; and the impact of sawn wood commodity chain performance on sawn wood supply sustainability be investigated.

\section{CONFLICT OF INTEREST}

The authors confirm that this article content has no conflict of interest.

\section{ACKNOWLEDGEMENTS}

The authors are grateful to School of Graduate studies, Makerere University for funding this study. We appreciate the cooperation of business units, individuals and institutions from which data for this research were collected. The findings are part of the $\mathrm{PhD}$ study at Makerere University.

\section{REFERENCES}

[1] Ministry of Water Lands and Environment. The National Forest Plan. Entebe: Uganda Government Printer 2002.

[2] Odokonyero GGO. Pitsawn timber production in the natural forests of Uganda. A forest harvesting case-study. Rome: FAO 2005.

[3] National Forestry Authority. Managing Central Forest Reserves for the people of Uganda: a strategic action plan for the period 2008/09 to 2012/13 with priorities for the first 5 years. Kampala: National Forestry Authority 2008.

[4] Asumadu K. Development of wood-based industries in SubSaharan Africa. A report prepared for the project: Lessons Learnt on Sustainable Forest Management in Africa. KLSA, AFORNET and FAO 2004.
[5] Beamon BM. Supply chain design and analysis: models and methods. Int J Prod Econ 1998; 55 (3): 281-94.

[6] van der Vorst JGAJ. Performance measurement in agri-food supply-chain networks: an overview. In: Ondersteijn CJM, Wijnands JHM, Huirne RBM and van Kooten O, Eds. Quantifying the agri-food supply chain. Netherlands: Springer 2006; pp. 13-24.

[7] Ribot JC. Theorizing access: Forest profits along Senegal's charcoal commodity chain. Dev Change 1998; 29: 307-41.

[8] Kambugu RK, Banana AY and Okure M. Uncovering the factors influencing profile of the sawn wood commodity chain in Uganda. Unpublished manuscript 2012.

[9] Kambugu RK, Banana A Y, Zziwa A, et al. The relative efficiency of sawmills operating in Uganda's softwood plantations. Ug J Agric Sci 2005; 11 (1): 14-9.

[10] Beamon B M. Measuring supply chain performance. Int J Oper Prod Manage 1999; 19 (3): 275-92.

[11] Chan FTS, Qi HJ. An innovative performance measurement method for supply chain management. Supply Chain Manag 2003; 8(3): 209-23.

[12] Chan FTS. Performance measurement in a supply chain. Int J Adv Manuf Tech 2003; 21: 534-48.

[13] Aramyan L, Ondersteijn C, van Kooten O, Lansink AO. Performance indicators in agri-food production chains. In: Ondersteijn CJM, Wijnands JHM, Huirne RBM and van Kooten O, Eds. Quantifying the agri-food supply chain. Netherlands: Springer 2006; pp. 47-64.

[14] Sustainability Institute. Commodity systems challenges: moving sustainability into the mainstream of natural resource economics [monograph on the internet]. Hartland, Vermont: Sustainability Institute; 2003. Available from: http://www.sustainer.org/pubs [cited 2005 Jan 18].

[15] Jones A, Seville D, Meadows D. Resource sustainability in commodity systems: The sawmill industry in the Northern Forest. Syst Dyn Rev 2002; 18(2): 171-204.

[16] Mendoza GA, Meimban RJ, Sprouse W, Luppold WG, Araman P. An integrated management support and production control system for hardwood forest products. Comput Ind 1991; 16: 343-51.

[17] Wadhwa V. Determination of the optimal performance of hardwood sawmills and its relationship to the metric "overrun". MSc. Thesis. The Pennsylvania State University 2007.

[18] Bédard P. Guidelines to better match resource characteristics, conversion technology and products. In: Baumgartner DM, Johnson LR and DePuit EJ, Eds. Proceedings of conference on Small Diameter Timber: Resource Management, Manufacturing, and Markets; 2002: Spokane, Washington: Washington State University Cooperative Extension 2002; pp. 219-25.

[19] Lowell EC, Green DW. Lumber recovery from small-diameter ponderosa pine from Flagstaff, Arizona. In: Vance Regina K, Edminster Carleton B, Covington, W Wallace, Blake Julie A, Comps. Proceedings on Ponderosa pine ecosystems restoration and conservation: steps toward stewardship; 2000; Flagstaff, AZ: U.S. Department of Agriculture, Forest Service, Rocky Mountain Research Station 2001; pp. 161-5.

[20] Westerman B. Optimizing the forest for sustainable management, improved manufacturing performance, and total profitability. In: Baumgartner DM, Johnson LR and DePuit EJ, Eds. Proceedings of conference on Small Diameter Timber: Resource Management, Manufacturing, and Markets; 2002: Spokane, Washington: Washington State University Cooperative Extension 2002; pp. 199218. 